\title{
Development of a CT-guided standard approach for tined lead implantation at the sacral nerve root S3 in minipigs for chronic neuromodulation
}

This article was published in the following Dove Press journal:

Research and Reports in Urology

28 September 2016

Number of times this article has been viewed

\author{
Elena Esra Foditsch' \\ Reinhold Zimmermann ${ }^{2}$ \\ 'Urology, Spinal Cord Injury and \\ Tissue Regeneration Center Salzburg, \\ Paracelsus Medical University, \\ ${ }^{2}$ University Clinic of Urology and \\ Andrology, Salzburg General Hospital, \\ Paracelsus Medical University, \\ Salzburg, Austria
}

Purpose: The aim of this study was to develop a controlled approach for sacral neuromodulation (SNM) to improve both nerve targeting and tined lead placement, for which a new computed tomography (CT)-guided implantation technique was analyzed in minipigs.

Materials and methods: This study included five female, adult Göttingen minipigs. In deep sedoanalgesia, the minipigs were placed in an extended prone position. Commercially available SNM materials were used (needle, introduction sheath, and quadripolar tined lead electrode). Gross anatomy was displayed by CT, and the nerves were bilaterally identified. The optimal angles to puncture the S3 foramen, the resulting access path, and the site for the skin incision were defined subsequently. The needle puncture and the tined lead placement were followed by successive CT scans/3D-reconstruction images. Once proper CT-guided placement of the needle and electrode was established, response to functional stimuli was intraoperatively checked to verify correct positioning.

Results: Successful bilateral tined lead implantation was performed in four out of five minipigs. Implantation was different from the clinical situation because the puncture was done from the contralateral side at a $30^{\circ}$ angle to the midline and $60^{\circ}$ horizontal angle to ensure both passage through the foramen and nerve access. Surgery time was 50-150 minutes. Stimulation response comprised a twitch of the perianal musculature and tail rotation to the contralateral side.

Conclusion: We have established a new, minimally invasive, highly standardized, CT-guided SNM electrode implantation technique. Functional outcomes are clearly defined and reproducible. All procedures can be performed without complications. Future chronic stimulation studies in minipigs can thereby be conducted using a controlled and highly standardized protocol.

Keywords: computed tomography, sacral nerve stimulation, large animal model

\section{Introduction}

In the field of functional urology, chronic stimulation of the sacral nerves has become one of the most accepted methods of treatment. ${ }^{1}$ Sacral neuromodulation (SNM) is a therapeutic tool for treating a broad spectrum of lower urinary tract dysfunctions. Urgency urinary incontinence, urgency and frequency syndromes, and nonobstructive urinary retention are indications for SNM according to guidelines. Lead implantation is regularly done under fluoroscopic control, but still under "blind" conditions, as the nerve cannot be visualized by conventional X-ray. On the contrary, computed tomography $(\mathrm{CT})$ can properly display the bony anatomy and nerves and may therefore be ideal to exactly implant leads. CT guidance allows precise anchoring of the leads; not only the bony foramina of the sacrum, but also details of the targeted nerve fibers, can be seen. ${ }^{2}$ The pig is a suitable animal model as the anatomical, physiological, and
Correspondence: Elena Esra Foditsch Urology, Spinal Cord Injury and Tissue Regeneration Center Salzburg, Paracelsus Medical University,Strubergasse 21, Salzburg 5020, Austria

Tel +43662242080895

Fax +4357255 27497

Email esra.foditsch@pmu.ac.at 
pharmacological characteristics of its lower urinary tract are considered more similar to that of humans than those of other animal models. ${ }^{3}$ In this study, we present a technique for a targeted, CT-guided tined lead electrode implantation for chronic SNM studies in a large animal model, the minipig.

\section{Materials and methods}

This study was approved by the Ethics and Deontology Committee for Research on Animals, Victor Babes University of Medicine, Timisoara, Romania, and is in compliance with the Association for Assessment of Laboratory Animal Care guidelines.

Five female Göttingen minipigs (Ellegaard Göttingen Minipigs A/S, Dalmose, Denmark), aged 6 months (weight: $21-26 \mathrm{~kg}$ ), were included. Prior to implantation, the health state of all animals was documented. Minipigs were prepared with intramuscular ketamine $(15 \mathrm{mg} / \mathrm{kg})$ and xylazine $(2 \mathrm{mg} / \mathrm{kg})$. Deep analgosedation (AS) was established and maintained by intravenous administration of propofol (10 mg/kg). Fentanyl $(0.05 \mathrm{mg} / \mathrm{kg})$ was given intravenously as analgesia prior to the surgery and, if needed, given for a second time during implantation.

Minipigs were placed in an extended prone position. An initial CT scan and 3D reconstruction of the bony pelvis was made, and the needle axis and angle were calculated and marked by a felt pen on the minipig's skin. The optimal pathway for the tined lead insertion was defined by the leading anatomical landmarks, ie, the neuroforamen (Figure 1) and both origin and course of the S3 root. Moreover, the diameters of the neuroforamen S3 were measured (Figure 2), and the course of the sacral root S3 was identified for documentation (Figure 3). The exact point of access was marked individually for each single minipig according to and in correlation with the CT scan and, if needed, under immediate CT control. The main calculation procedure depended on the course of the sacral root as we intended to place the lead as close and parallel as possible. Accordingly, we inserted the puncture needle in a defined angulation of $30^{\circ}$ horizontal, $60^{\circ}$ to the midline, and from the contralateral side. Next, a rigid 0.014-inch $(0.035 \mathrm{~cm})$ guidewire was inserted according to the Seldinger technique. An introducer sheath was thereafter inserted into the neuroforamen and, after the positions were proven by CT, the guidewire was removed. Both guidewire and sheath were from the Lead Introducer Kit 3550-18 (Medtronic Inc, Minneapolis, MN, USA). A tined quadripolar lead (Medtronic tined lead 3889; Medtronic Inc) was then placed through the sheath, and the proper position relative to the $\mathrm{S} 3$ root was confirmed by another CT scan (Figure 4). Finally, the introducer sheath was removed and a final CT examination was conducted. All SNM lead placement steps are shown stepwise in Figure 5. The first test of stimulation verification was done intraoperatively by electrical stimulation with $50 \mathrm{~Hz}$ for 450 milliseconds at $1-2 \mathrm{~V}$ to provoke the maximum effect by monitoring the contraction of the perianal muscles, tail rotation, and claw rotation. The implantable pulse generator (IPG) and extension cables were implanted bilaterally into the flank region. The minipigs were covered with an analgesia and antibiotic regime for five consecutive days postimplantation.
A

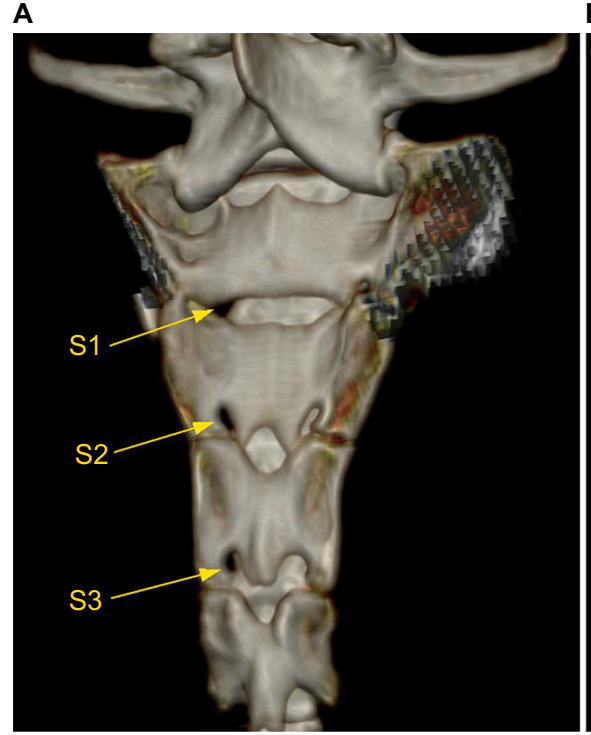

B

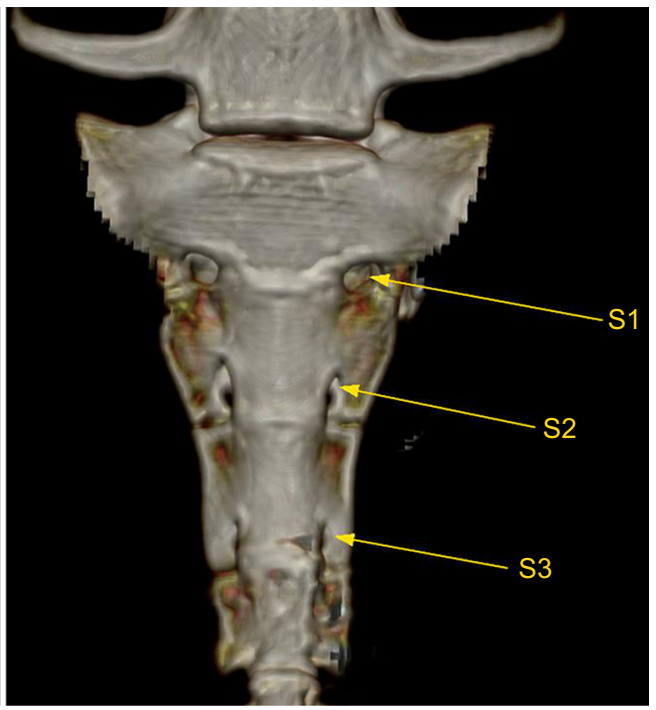

Figure I Bony anatomy of the sacrum displaying the neuroforamina I-3 (SI, S2, and S3) of a minipig.

Note: The dorsal (A) and the ventral (B) views of the SI-S3 neuroforamina are displayed. 

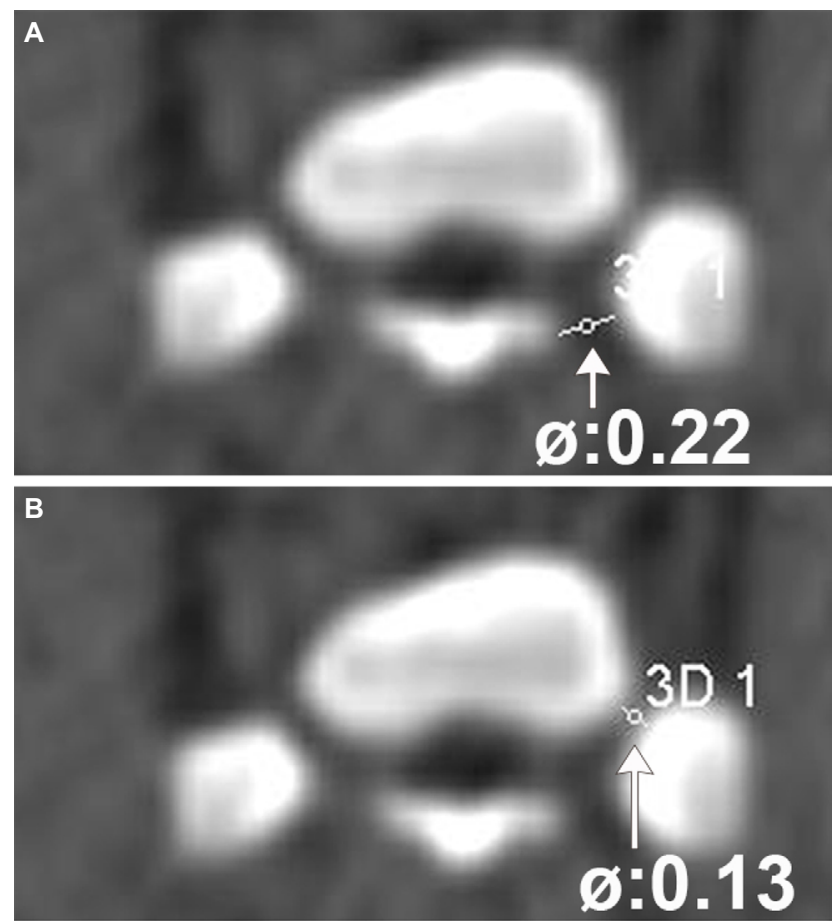

Figure 2 Diameters of the neuroforamen $\mathrm{S} 3$ of one selected minipig.

Notes: The outer (A) and inner (B) diameters of the neuroforamen S3. The outer diameter is $0.22 \mathrm{~cm}$ (arrow); the inner diameter is $0.13 \mathrm{~cm}$ (arrow).

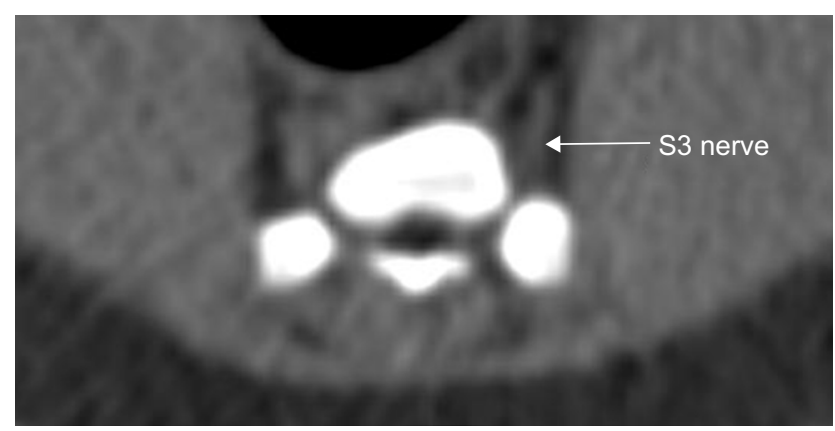

Figure 3 Course of the sacral nerve root S3 (arrow) of one selected minipig.

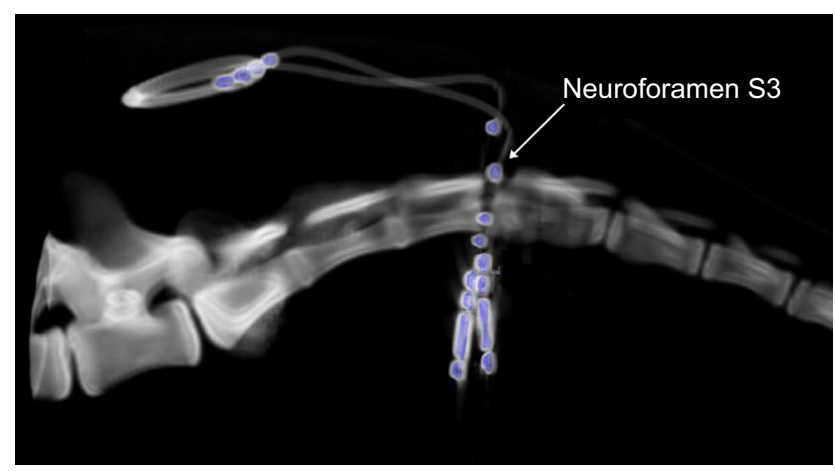

Figure 4 Final CT reconstruction of bilaterally implanted tined leads (in blue) at the neuroforamen $\mathrm{S} 3$.

Abbreviation: $\mathrm{CT}$, computed tomography.
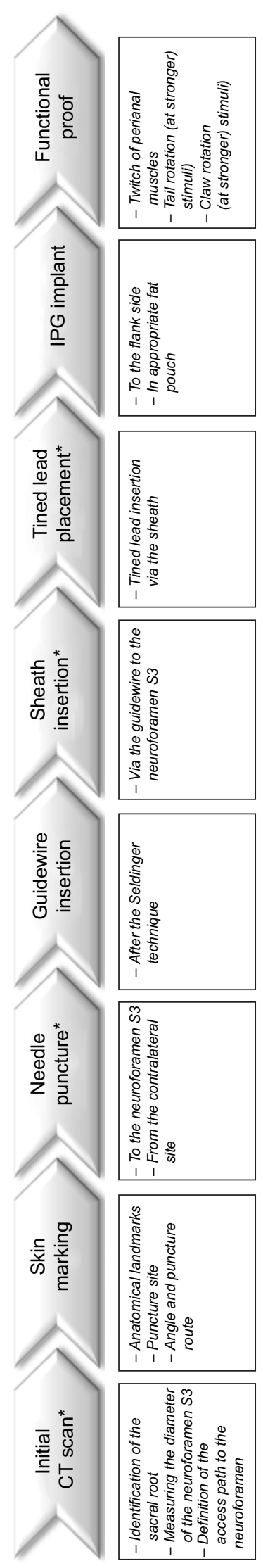

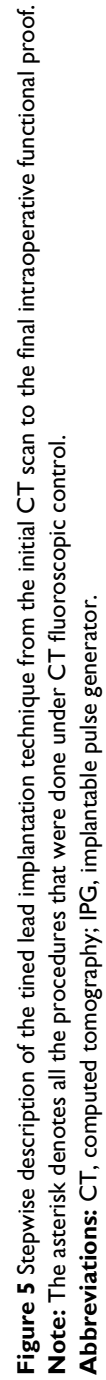


One week after implantation, stimulation was initiated. For this purpose, the minipigs were placed in a hammock. Leads were activated and the somatosensory response was tested. Motor responses comprised a twitch of the perianal musculature and, at stronger stimulation impulses, tail and claw rotations. The final stimulation for chronic neuromodulation was set to just below threshold.

After 3.5 months, the positions of the leads were reevaluated by a control CT scan to confirm stable electrode position by comparison with the position in the first control CT scan.

\section{Results}

The duration needed for bilateral implantation was 50-150 minutes. Nerves could be clearly visualized by CT. A shortcoming was that due to the limited size of the minipigs' neuroforamina relative to the sheath and lead diameters, the puncture had to be performed from the contralateral side to ensure both passage through the foramen and nerve access. In the majority of the cases, the sheath did not pass through the neuroforamen smoothly, and angulation of the needle/sheath needed one or more corrections as the diameter of the neuroforamen was too narrow and instruments too large as they are designed for human application. By selecting an optimal and straightforward pathway, avoiding any small deviation, the final passage through the foramen and positioning of the lead alongside the $\mathrm{S} 3$ nerve course is possible. Intraoperative stimulation responses were observed in all animals as twitch of the perianal musculature and, at stronger stimuli, tail and claw rotations. One tined lead failed to be properly fixed as its position relative to $\mathrm{S} 3$ was too superficial due to the inappropriate total length and the required insertion depth considering the lead's position versus S3. Finally, four minipigs were implanted bilaterally and one unilaterally, as shown in Table 1, apart from evaluating all final stimulation parameters for chronic neuromodulation. The control CT after 3.5 months showed correct tined lead positions in all five minipigs. None of the leads migrated in relation to the first control CT.

\section{Discussion}

CT-guided electrode implantation seems to be feasible in minipigs. Deep AS was chosen as the optimal sedation regime as it has a strong analgesic effect. Moreover, it maintains the reflexes, which are necessary for the initial evaluation of correct lead placement. Independent breathing is another advantage when using deep AS, as consecutive CT scans are necessary. We could use standard, "Conformité Européene" (CE, meaning "European Conformity")-marked implant kits, tined leads, and IPGs, which allows a fast translation of results to the clinics. Nevertheless, there are differences in the approach between the technical details applicable for minipigs and humans. The lead implantation has to be performed from the contralateral side in minipigs in contrast to the ipsilateral approach in humans. Moreover, the bony dimensions of the neuroforamen S3 need to be preevaluated in the initial CT scan to avoid mismatches. This is especially recommended for younger minipigs ( $<6$ months of age). Up to date, only few publications have studied the outcomes of SNM in pigs. ${ }^{4,5}$ However, these studies contained nonsurvival designs, with varying techniques underlying lead implantation into the sacral nerve root S3. Only one study implanted tined leads by conventional percutaneous implantation with fluoroscopy, ${ }^{4}$ while the others used open surgery. The functional stimuli response analogs to SNM are clearly visible as perianal muscle contractions and, at higher stimulation impulses, tail and claw rotations. These observations are congruent with those in literature. ${ }^{5}$

\section{Conclusion}

We have established a new, minimally invasive, standardized, CT-guided tined lead implantation technique for chronic SNM in minipigs. Functional outcomes are clearly defined and reproducible. All procedures can be performed without complications and result in proper lead positioning without migration. We have generated a reproducible, but nevertheless clear, procedure for chronic stimulation studies in minipigs. It follows current requirements of laboratory animal use as it minimizes the durations of anesthesia, surgery, and suffering.

\section{Acknowledgments}

This study was supported by a grant for tined leads and implantable pulse generators by Medtronic Inc, Minneapolis, MN, USA. The authors wish to thank Gratian Miclaus, MD, SCM Neuromed, Timisoara, Romania, for his excellent CT conductance, image acquisition, and processing. Furthermore,

Table I Lead configurations applied for chronic SNM

\begin{tabular}{lllll}
\hline ID & Tined lead configuration & SNM parameters & Location of the IPG & Mode of SNM \\
\hline I & I: $-; 3:+$ & R: $10 \mathrm{~Hz}, 210 \mathrm{~ms}, 0.1 \mathrm{~V} ; \mathrm{L}: 10 \mathrm{~Hz}, 210 \mathrm{~ms}, 0.8 \mathrm{~V}$ & Rostral at level L2/L3 & Bilateral \\
2 & I: $-; 3:+$ & R: $10 \mathrm{~Hz}, 210 \mathrm{~ms}$, I V & Rostral at level L2/L3 & Unilateral \\
3 & I: $-; 3:+$ & R: $10 \mathrm{~Hz}, 210 \mathrm{~ms}, 0.3 \mathrm{~V} ; \mathrm{L}: 10 \mathrm{~Hz}, 210 \mathrm{~ms}$, I V & Lateral at level L2/L3 & Bilateral \\
4 & I: $-; 3:+$ & R: $10 \mathrm{~Hz}, 210 \mathrm{~ms}, I \mathrm{~V} ; \mathrm{L}: 10 \mathrm{~Hz}, 210 \mathrm{~ms}, 0.4 \mathrm{~V}$ & Lateral at level L2/L3 & Bilateral \\
5 & I: $-; 3:+$ & R: $10 \mathrm{~Hz}, 210 \mathrm{~ms}$, I V; L: $10 \mathrm{~Hz}, 210 \mathrm{~ms}$, I V & Lateral at level L2/L3 & Bilateral \\
\hline
\end{tabular}

Abbreviations: ID, identity number; IPG, implantable pulse generator, L, left side; R, right side; SNM, sacral neuromodulation. 
we are grateful to Dr Sophina Bauer, Professor Günter Janetschek (Paracelsus Medical University) and Professor Sébastien Couillard-Despres (Institute for Experimental Neuroregeneration, Spinal Cord Injury and Tissue Regeneration Center Salzburg, Paracelsus Medical University, Salzburg, Austria) for their valuable advice. Finally, we would like to express our appreciation to Professor Ioan Hutu, Dr Irina Patras, and the team of the Horia Cernescu Animal Facility of the Banat University of Agriculture and Veterinary Sciences, Timisoara, Romania, for their excellent care of the minipigs.

\section{Disclosure}

Reinhold Zimmermann works as a consultant and proctor for Medtronic. Elena Esra Foditsch reports no conflicts of interest in this work. The authors report no other conflicts of interest in this work.

\section{References}

1. Spinelli M, Giardiello G, Gerber M, Arduini A, van den Hombergh U, Malaguti S. New sacral neuromodulation lead for percutaneous implantation using local anesthesia: description and first experience. J Urol. 2003;170(5):1905-1907.

2. Meissnitzer T, Trubel S, Posch-Zimmermann R, Meissnitzer MW. CTguided lead placement for selective sacral neuromodulation to treat lower urinary tract dysfunctions. AJR Am J Roentgenol. 2015;205(5): 1139-1142.

3. Foditsch EE, Hoinoiu B, Janetschek G, Zimmermann RP. Laparoscopic placement of a tined lead electrode on the pudendal nerve with urodynamic monitoring of bladder function during electrical stimulation: an acute experimental study in healthy female pigs. Springerplus. 2014; 3:309.

4. Meurette G, Blanchard C, Duchalais-Dassonneville E, et al. Sacral nerve stimulation enhances epithelial barrier of the rectum: results from a porcine model. Neurogastroenterol Motil. 2012;24(3): 267-273,e110.

5. Kaufmann S, Naumann CM, Hamann MF, et al. Unilateral vs bilateral sacral neuromodulation in pigs with formalin-induced detrusor hyperactivity. BJU Int. 2009;103(2):260-263.
Research and Reports in Urology

\section{Publish your work in this journal}

Research and Reports in Urology is an international, peer-reviewed, open access journal publishing original research, reports, editorials, reviews and commentaries on all aspects of adult and pediatric urology in the clinic and laboratory including the following topics: Pathology, pathophysiology of urological disease; Investigation and treatment of

\section{Dovepress}

urological disease; Pharmacology of drugs used for the treatment of urological disease. The manuscript management system is completely online and includes a very quick and fair peer-review system, which is all easy to use. Visit http://www.dovepress.com/testimonials.php to read real quotes from published authors. 